University of Nebraska - Lincoln

DigitalCommons@University of Nebraska - Lincoln

Recombinant paraoxonase 1 protects against sarin and soman toxicity following microinstillation inhalation exposure in guinea pigs

\author{
Manojkumar Valiyaveettil \\ Walter Reed Army Institute of Research \\ Yonas Alamneh \\ Walter Reed Army Institute of Research \\ Peter Rezk \\ US Army Medical Research Institute of Chemical Defense \\ Michael W. Perkins \\ US Army Medical Research Institute of Chemical Defense \\ Alfred M. Sciuto \\ US Army Medical Research Institute of Chemical Defense \\ See next page for additional authors \\ Follow this and additional works at: https://digitalcommons.unl.edu/usarmyresearch \\ Part of the Operations Research, Systems Engineering and Industrial Engineering Commons
}

Valiyaveettil, Manojkumar; Alamneh, Yonas; Rezk, Peter; Perkins, Michael W.; Sciuto, Alfred M.; Doctor, Bhupendra P.; and Nambiar, Madhusoodana P., "Recombinant paraoxonase 1 protects against sarin and soman toxicity following microinstillation inhalation exposure in guinea pigs" (2011). US Army Research. 157.

https://digitalcommons.unl.edu/usarmyresearch/157

This Article is brought to you for free and open access by the U.S. Department of Defense at DigitalCommons@University of Nebraska - Lincoln. It has been accepted for inclusion in US Army Research by an authorized administrator of DigitalCommons@University of Nebraska - Lincoln. 


\section{Authors}

Manojkumar Valiyaveettil, Yonas Alamneh, Peter Rezk, Michael W. Perkins, Alfred M. Sciuto, Bhupendra P. Doctor, and Madhusoodana P. Nambiar 


\title{
Recombinant paraoxonase 1 protects against sarin and soman toxicity following microinstillation inhalation exposure in guinea pigs ${ }^{\text {is }}$
}

\author{
Manojkumar Valiyaveettil ${ }^{\mathrm{a}}$, Yonas Alamneh ${ }^{\mathrm{a}}$, Peter Rezk ${ }^{\mathrm{b}}$, Michael W. Perkins $^{\mathrm{b}}$, \\ Alfred M. Sciuto ${ }^{\mathrm{b}}$, Bhupendra P. Doctor ${ }^{\mathrm{a}, *}$, Madhusoodana P. Nambiar ${ }^{\mathrm{a}, \mathrm{c}}$ \\ a Closed-Head Injury Branch, Center for Military Psychiatry and Neuroscience, Walter Reed Army Institute of Research, Silver Spring, MD 20910, USA \\ ${ }^{\mathrm{b}}$ Analytical Toxicology Division, US Army Medical Research Institute of Chemical Defense, Aberdeen Proving Ground, MD 21010, USA \\ ${ }^{\mathrm{c}}$ Department of Medicine, Uniformed Services University of the Health Sciences, Bethesda, MD 20814, USA
}

\section{A R T I C L E I N F O}

\section{Article history:}

Received 12 January 2011

Received in revised form 3 February 2011

Accepted 4 February 2011

Available online $\mathrm{xxx}$

\section{Keywords:}

Catalytic bioscavenger

Paraoxonase 1

Recombinant protein

Trichoplusia ni larvae

Chemical warfare nerve agents

\begin{abstract}
A B S T R A C T
To explore the efficacy of paraoxonase 1 (PON1) as a catalytic bioscavenger, we evaluated human recombinant PON1 (rePON1) expressed in Trichoplusia ni larvae against sarin and soman toxicity using microinstillation inhalation exposure in guinea pigs. Animals were pretreated intravenously with catalytically active rePON1, followed by exposure to $1.2 \mathrm{X} \mathrm{LCt}_{50}$ sarin or soman. Administration of 5 units of rePON1 showed mild increase in the blood activity of the enzyme after $30 \mathrm{~min}$, but protected the animals with a significant increase in survival rate along with minimal signs of nerve agent toxicity. Recombinant PON1 pretreated animals exposed to sarin or soman prevented the reduction of blood $\mathrm{O}_{2}$ saturation and pulse rate observed after nerve agent exposure. In addition, rePON1 pretreated animals showed significantly higher blood PON1, acetylcholinesterase (AChE), and butyrylcholinesterase activity after nerve agent exposure compared to the respective controls without treatments. AChE activity in different brain regions of rePON1 pretreated animals exposed to sarin or soman were also significantly higher than respective controls. The remaining activity of blood PON1, cholinesterases and brain AChE in PON1 pretreated animals after nerve agent exposure correlated with the survival rate. In summary, these data suggest that human rePON1 protects against sarin and soman exposure in guinea pigs.
\end{abstract}

(c) 2011 Elsevier Ireland Ltd. All rights reserved.

\section{Introduction}

Human serum paraoxonase 1 (PON1, EC 3.1.8.1) is a polymorphic enzyme that is expressed mainly in the liver, secreted to blood, and associated with high density lipoproteins (HDL) (Costa et al., 2003; Humbert et al., 1993; Primo-Parmo et al., 1996). PON1 associated with HDL is a $45 \mathrm{kDa}$ arylesterase which has been reported to protect low density lipoproteins from oxidative modifications and thus exerts the anti-atherogenic property of PON1 in atherosclerosis and cardiovascular diseases (Costa et al., 2005a; Harel et al.,

Abbreviations: PON1, paraoxonase 1; HDL, high density lipoprotein; rePON1, recombinant PON1; OP, organophosphate; CWNA, chemical warfare nerve agent; $\mathrm{AChE}$, acetylcholinesterase; $\mathrm{BChE}$, butyrylcholinesterase; p-NPA, p-nitrophenylacetate; BCA, bicinchoninic acid; Sarin, 2-(fluoro-methylphosphoryl)oxypropane; Soman, 2-(fluoromethylphosphoryl)oxy-3,3-dimethylbutane.

Disclosure: The opinions and assertions contained herein are the private views of the authors and are not to be construed as official or as reflecting the views of the Army, the Navy, or the Department of Defense, USA.

* Corresponding author at: 503 Robert Grant Avenue, Walter Reed Army Institute of Research, Silver Spring, MD 20910. Tel.: +1 301319 9548; fax: +1 3013199404.

E-mail addresses: bpdoctor@verizon.net (B.P. Doctor), madhusoodana.nambiar@amedd.army.mil (M.P. Nambiar).
2004; Josse and Masson, 2001; Mackness et al., 2002). PON1 has also been described as a potential catalytic bioscavenger by a number of groups due to its capacity to hydrolyze organophosphates (OPs) and chemical warfare nerve agents (CWNAs) (Costa et al., 2005b; Furlong et al., 2005; Otto et al., 2009; Otto et al., 2010; Stevens et al., 2008). It can hydrolyze large amounts of OPs and CWNAs compared to the stoichiometric bioscavenger human butyrylcholinesterase (BChE), which acts in a 1:1 ratio, and would thus require smaller doses and would reduce the cost of treatment (Doctor et al., 1991; Doctor and Saxena, 2005; Lenz et al., 2005; Lenz et al., 2007; Rochu et al., 2007).

The mechanism of action of OPs and CWNAs has been well described as the irreversible inhibition of acetylcholinesterase (AChE) in the central and peripheral nervous system leading to abnormal accumulation of acetylcholine resulting in overstimulation of cholinergic transmission (Aldridge and Davison, 1953; Bajgar, 2004; Flynn and Wecker, 1986). An effective countermeasure strategy for OP and CWNA toxicity has been centered on the development of catalytic bioscavenger enzymes as pretreatments which can rapidly hydrolyze large amounts of OPs and CWNAs in the blood before they reach their targets. Recent research and development identified human PON1 as a suitable candidate catalytic bioscavenger against OP and CWNA mediated toxicity (Costa 
et al., 2005b; Furlong et al., 2005; Li et al., 1995; Otto et al., 2009; Otto et al., 2010; Rochu et al., 2007; Stevens et al., 2008). Most of these studies were either performed under in vitro conditions, or in rodent models of OP toxicity (Duysen et al., 2010; Fu et al., 2005; Li et al., 1995; Wang et al., 2010). We also reported efficient hydrolysis of the CWNA tabun in comparison to sarin and soman by PON1 using in vitro analysis (Valiyaveettil et al., 2010). Efficacy of PON1 against CWNA toxicity in animal models needs to be investigated.

Recently, we have reported the protective efficacy of human and rabbit serum purified PON1 against sarin and soman inhalation toxicity in guinea pigs using microinstillation technology (Valiyaveettil et al., 2011). Although serum purified enzymes can be used for treatment, recombinant enzymes are preferred for the ease of large scale production and elimination of polymorphism and heterogeneity. Pooling of serum from multiple donors may lead to purification of multiple PON1 mutants including one which has lower catalytic activity. Another major concern with the use of human derived protein therapeutics is the inherent potential for infectious agents like hepatitis and human immunodeficiency virus (Grillberger et al., 2009). Nevertheless, recombinant enzymes may have difference in stability, pharmacokinetics and efficacy, which need to be investigated. Significant hydrolysis of sarin and soman by human recombinant PON1 (rePON1) expressed in Trichoplusia ni larvae by in vitro analysis prompted us to further investigate the protective efficacy against CWNA toxicity (Valiyaveettil et al., 2010). In this paper, we evaluated the efficacy of human rePON1 against sarin and soman toxicity in guinea pigs using microinstillation inhalation exposure technology (Nambiar et al., 2007; Nambiar et al., 2006).

\section{Materials and methods}

\subsection{Materials}

P-nitrophenylacetate (p-NPA), phenylacetate, acetylthiocholine, butyrylthiocholine, tetra monoisopropyl pyrophosphortetramide, huperzine A, 5,5'-dithiobis (2-nitrobenzoic acid), and 4,4'-dipyridyl disulfide, 4,4'-dithiodipyridine were purchased from Sigma (St. Louis, MO). Tissue protein extraction reagent and bicinchoninic acid (BCA) protein assay kit were purchased from Pierce (Rockford, IL). CWNAs, sarin (99.8\% pure) and soman (99.6\% pure) were obtained from Edgewood Chemical and Biological Center and used at US Army Medical Research Institute of Chemical Defense (USAMRICD), Aberdeen Proving Ground, MD.

\subsection{Animals}

All animal procedures were performed at USAMRICD in compliance with the Animal Welfare Act and other federal statutes and regulations relating to animals and experiments involving animals and adhered to principles stated in the Guide for the Care and Use of Laboratory Animals (NRC Publication 1996 edition) with an approved Institutional Animal Care and Use Committee protocol. Male Hartley guinea pigs (250-300 g, Charles River Laboratories, Wilmington, MA) were used for the studies.

\subsection{Expression and purification of recombinant human PON1}

Recombinant PON1 was expressed in T. ni larvae and was purified as described earlier in collaboration with Chesapeake PERL (Savage, MD) (Otto et al., 2010; Valiyaveettil et al., 2010). Briefly, baculovirus expression vector containing human PON1 cDNA (encoding wild type human PON1 with Q192 polymorphism) was orally infected to larvae followed by incubation at controlled conditions for $96 \mathrm{~h}$. The harvested larvae were stored under frozen conditions until the recovery of PON1 enzyme. The extraction and purification of rePON1 was performed by using multiple chromatography procedures as described earlier (Otto et al., 2010; Valiyaveettil et al., 2010). The purity of rePON1 was analyzed by SDS-PAGE and Western blotting. The catalytic activity of purified rePON1 (>99\% pure) was analyzed using p-NPA substrate and expressed as units/mg protein or units/ml (Valiyaveettil et al., 2010). Enzyme activity was calculated with the molar extinction coefficient $\left(18 \mathrm{mM}^{-1} \mathrm{~cm}^{-1}\right)$ of p-nitrophenol. The purified rePON1 showed a specific activity of 8.5 units/mg protein.

\subsection{Sarin and soman microinstillation inhalation exposure}

Control and rePON1 pretreated guinea pigs were exposed to sarin and soman using the microinstillation inhalation exposure methodology as described earlier
(Nambiar et al., 2007; Nambiar et al., 2006). Briefly, the animals were anesthetized (telazol, $40 \mathrm{mg} / \mathrm{kg}$, i.m. and medetomidine, $0.125 \mathrm{mg} / \mathrm{kg}$, s.c.) and saline or rePON1 (5 units) were administered through saphenous vein using a 28.5 gauge needle. Ear blood was collected from animals before and after the administration of rePON1. Animals were intubated and a microcatheter was inserted and placed $2 \mathrm{~cm}$ above the bifurcation of the trachea for aerosolization of the CWNA. Thirty minutes after administration of rePON1, the animals were exposed to sarin $\left(846 \mathrm{mg} / \mathrm{m}^{3}\right)$ or soman $\left(841 \mathrm{mg} / \mathrm{m}^{3}\right)$ using the microinstillation equipment (Trudell Medical, Ontario, Canada) with a pulse rate of 40 pulses/min for $2-4$ min (Che et al., 2008; Perkins et al., 2010). Blood and tissue samples were collected from terminally ill animals. The surviving animals were allowed to recover for $24 \mathrm{~h}$, euthanized by exsanguination and blood and tissues were collected for biochemical analysis.

\subsection{Pulse rate and blood $\mathrm{O}_{2}$ saturation measurement}

The blood $\mathrm{O}_{2}$ saturation (measured as \% saturation of peripheral oxygen, $\mathrm{SpO}_{2}$ ) and pulse rate (measured as beats per min, bpm) of the animals were recorded by using a pulse oximeter (Nonin Medical Instruments, Minneapolis, MN). The data were recorded at pre-intubation, post-intubation and $30 \mathrm{~s}$ intervals during and after exposure to CWNA for $15 \mathrm{~min}$. Mean \pm SEM values were plotted against time using GraphPad Prism software.

\subsection{Analysis of blood and brain enzyme activity}

Blood samples collected at various time points were diluted with de-ionized water. Brain tissue was dissected into different regions (frontal cortex, hind cortex, mid brain, cerebellum and hippocampus) and homogenized with 1:7 (wt/vol) tissue protein extraction reagent. The activity of PON1, AChE and BChE in the blood and AChE in the brain was determined as described earlier (Ellman et al., 1961; Valiyaveettil et al., 2011). Protein content in the brain samples was estimated by BCA protein assay kit. The activity of various enzymes in the blood and brain was expressed as $\mu \mathrm{mol} / \mathrm{min} / \mathrm{ml}$ or $\mu \mathrm{mol} / \mathrm{min} / \mathrm{mg}$ protein, respectively.

\subsection{Data analysis}

The animal survival data was plotted using Kaplan-Meier method and analyzed by Logrank test. The pulse rate and blood $\mathrm{O}_{2}$ saturation data at multiple time points were analyzed by two-way ANOVA with Bonferroni post-test. Blood and brain enzyme activity data were analyzed by using Mann-Whitney test.

\section{Results}

\subsection{Recombinant human PON1 protects against sarin and soman toxicity}

The survival data of guinea pigs pretreated with 5 units of rePON1 ( $600 \mu \mathrm{g}$ of protein) followed by exposure to $846 \mathrm{mg} / \mathrm{m}^{3}$ of sarin or $841 \mathrm{mg} / \mathrm{m}^{3}$ of soman are shown in the Kaplan-Meier curve (Fig. 1). Most of the control animals exposed to sarin or soman without any treatment died within 10-15 min, while majority of rePON1 pretreated animals exposed to sarin or soman survived for $24 \mathrm{~h}$. The non-surviving animals in rePON1 pretreated group died 2-4 h after CWNA exposure. Guinea pigs pretreated with 5 units of rePON1 and then exposed to $846 \mathrm{mg} / \mathrm{m}^{3}$ sarin showed $\sim 80 \%$ survival rate that is significantly higher than that seen in control animals exposed to sarin $(p=0.009)$. In animals exposed to $841 \mathrm{mg} / \mathrm{m}^{3}$ of soman, rePON1 pretreatment showed a $\sim 71 \%$ survival rate that was significant compared to untreated controls $(p=0.015)$. The animals that survived for $24 \mathrm{~h}$ in both sarin and soman groups were healthy and active.

\subsection{Recovery of pulse rate and blood $\mathrm{O}_{2}$ saturation in rePON1 pretreated guinea pigs exposed to CWNAs}

Guinea pigs exposed to sarin $\left(846 \mathrm{mg} / \mathrm{m}^{3}\right)$ showed a gradual drop in the heart rate during the entire 15 min of recording until the death of the animal, as reported previously (Valiyaveettil et al., 2011) (Fig. 2A). Recombinant PON1 pretreated animals exposed to sarin showed a similar decrease in the pulse rate up to $5 \mathrm{~min}$, 


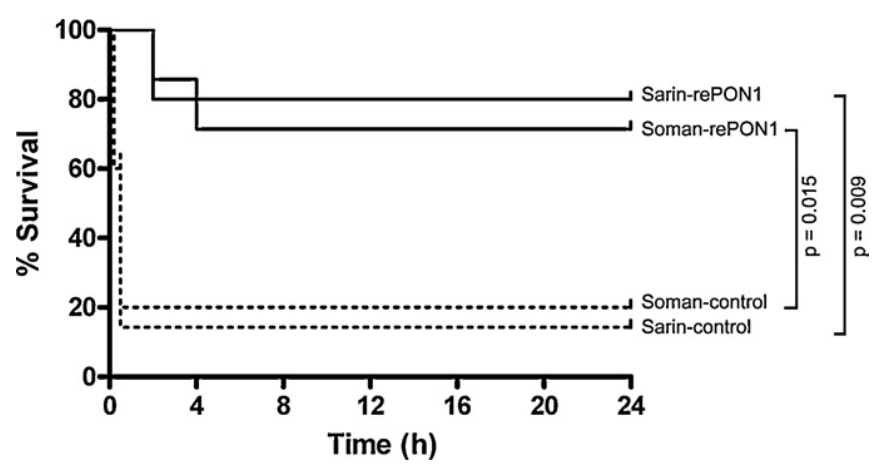

Fig. 1. Kaplan-Meier survival curve of guinea pigs pretreated with rePON1 and exposed to sarin and soman. Male Hartley guinea pigs were intravenously administered with saline or human recombinant PON1 (5 units) and 30 min later exposed to $846 \mathrm{mg} / \mathrm{m}^{3}$ of sarin or $841 \mathrm{mg} / \mathrm{m}^{3}$ of soman using microinstillation method as described in "Section 2". The surviving animals were allowed to recover for $24 \mathrm{~h}$. The percentage of survival of guinea pigs was plotted against time in GraphPad Prism using Kaplan-Meier survival curve and the statistical significance was analyzed by Logrank test. $n=14$ for saline controls exposed to sarin; $n=10$ for saline controls exposed to soman; $n=5$ for human recombinant PON1 (rePON1) exposed to sarin, $n=7$ for rePON1 exposed to soman.

which returned back to baseline by $8 \mathrm{~min}$ (Fig. 2A). The pulse rate in rePON1 pretreated animals exposed to sarin showed a statistically significant increase $10 \mathrm{~min}$ after the start of sarin exposure compared to the respective sarin controls (Fig. 2A). In the case of soman $\left(841 \mathrm{mg} / \mathrm{m}^{3}\right)$, the control guinea pigs showed a sharp drop in pulse rate for the first $5 \mathrm{~min}$. Pulse rate tend to return back, but remained below baseline levels up to $10 \mathrm{~min}$ and then decreased further until the death of the animal (Fig. 2B). Pulse rates in animals pretreated with rePON1 and exposed to soman showed a relatively lesser decrease and were quickly returned and maintained at baseline levels and that was statistically significant compared to untreated soman controls from $10 \mathrm{~min}$ after exposure (Fig. 2B).

The blood $\mathrm{O}_{2}$ saturation curve of sarin exposed animals showed a decrease till the end of $15 \mathrm{~min}$, although there was a drift toward normal levels at $7.5 \mathrm{~min}$ (Fig. 2C). Recombinant PON1 pretreated animals exposed to sarin showed a drop in the blood $\mathrm{O}_{2}$ saturation that peaked around $6 \mathrm{~min}$ and then returned back to baseline at $10 \mathrm{~min}$ and maintained until $15 \mathrm{~min}$ of recording. The blood $\mathrm{O}_{2}$ saturation at $10,11,14$ and $15 \mathrm{~min}$ after sarin exposure in rePON1 pretreated animals was significantly higher than the respective sarin controls (Fig. 2C). In soman exposed animals, the blood $\mathrm{O}_{2}$ saturation curve showed a pattern resembling pulse rate with a decrease at $4-5 \mathrm{~min}$ and a trend of returning back to baseline at 8-9 min (Fig. 2D). Recombinant PON1 pretreated animals exposed to soman also showed a pattern similar to pulse rate that returned back to baseline at $8 \mathrm{~min}$ and that was significantly higher than the respective soman controls at 11 and $15 \mathrm{~min}$ (Fig. 2D). The restoration of blood $\mathrm{O}_{2}$ saturation and pulse rate in rePON1 pretreated guinea pigs exposed to sarin or soman correlated with the increase in survival rate.
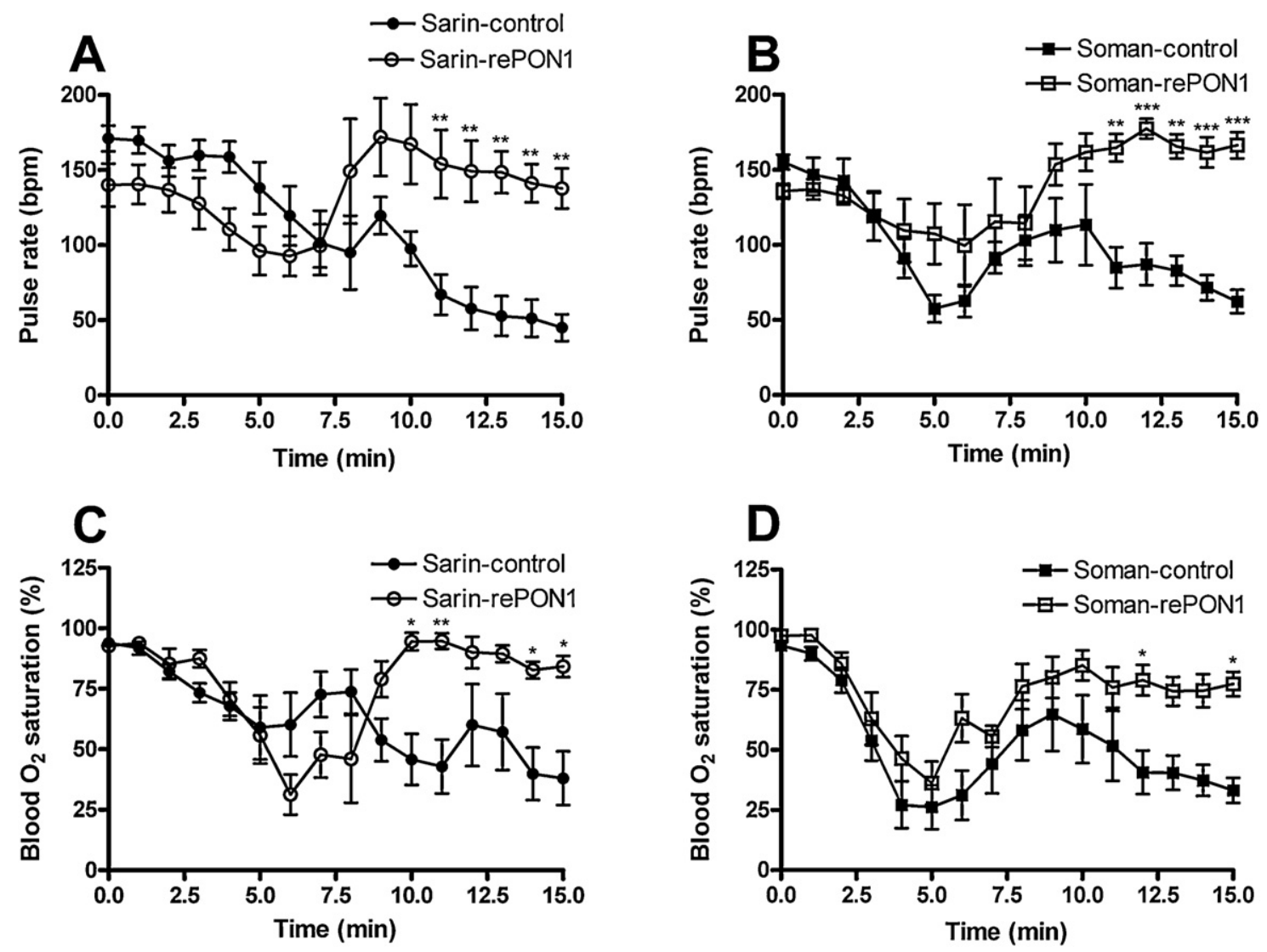

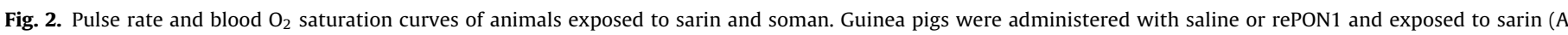

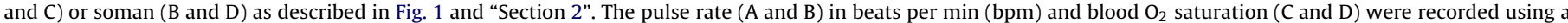

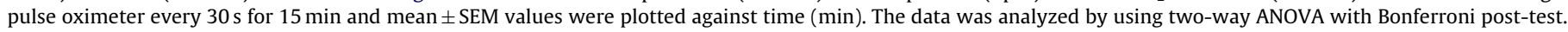

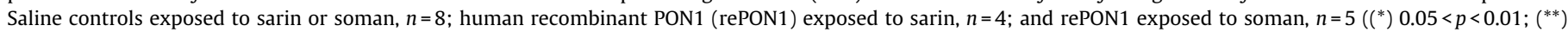
$0.01<p<0.001 ;(* * *) p<0.001)$. 

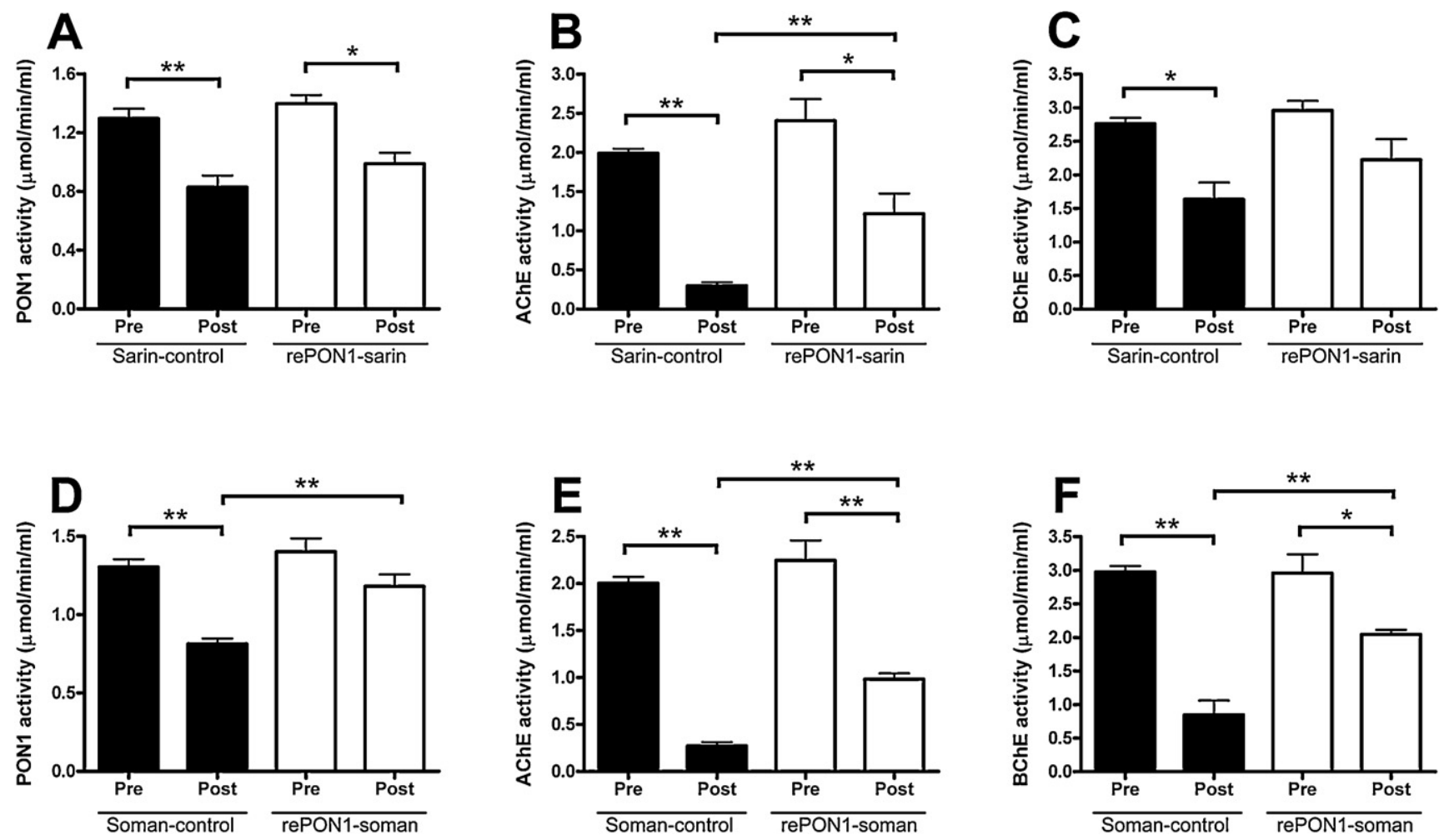

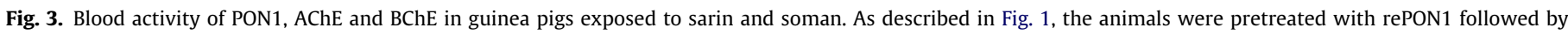

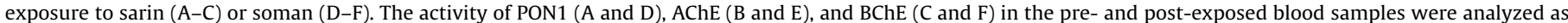
described in "Section 2". The results were expressed as $\mu \mathrm{mol} / \mathrm{min} / \mathrm{ml}$ of blood $\left(n=6\right.$ for control, and $4-5$ for rePON1; $\left.\left({ }^{*}\right) 0.05<p<0.01 ;(* *) 0.01<p<0.001\right)$.

\subsection{Activity of PON1, AChE and BChE in the blood of guinea pigs treated with rePON1and exposed to sarin and soman}

As reported earlier, the activity of PON1, AChE and BChE in the blood of guinea pigs exposed to sarin $\left(846 \mathrm{mg} / \mathrm{m}^{3}\right)$ or soman $\left(841 \mathrm{mg} / \mathrm{m}^{3}\right)$ showed a significant reduction compared to the respective controls (Valiyaveettil et al., 2011) (Fig. 3). Administration of rePON1 showed a marginal insignificant increase in the activity of PON1 and AChE in the blood of guinea pigs (Figs. 3A, $\mathrm{B}, \mathrm{D}$, and E), while blood BChE activity was unaltered (Figs. $3 \mathrm{C}$ and F). Recombinant PON1 pretreated animals exposed to sarin or soman also showed significant decreases in blood PON1, AChE and $\mathrm{BChE}$ activities, but this decrease was considerably lower than that of respective nerve agent exposed controls (Fig. 3). The residual blood PON1, AChE and BChE activities in rePON1 pretreated animals exposed to sarin or soman correlated with the increased survival rate after CWNA exposure.

\subsection{Brain AChE activity in rePON1 pretreated sarin and soman exposed guinea pigs}

Guinea pigs exposed to sarin or soman showed a significant reduction in the activity of $\mathrm{AChE}$ in different regions of the brain as observed earlier (Valiyaveettil et al., 2011) (Fig. 4). AChE activity in most of the brain regions of rePON1 pretreated animals exposed to sarin was significantly higher than that of nerve agent controls (Figs. 4A-E). The frontal cortex of PON1 pretreated animals exposed to sarin showed AChE activity similar to that of unexposed controls (Fig. 4A). In the case of soman, all the brain regions of rePON1 pretreated animals showed significantly higher AChE activity compared to nerve agent controls (Figs. 4A-E). Recombinant PON1 pretreated animals exposed to sarin or soman retained $\sim 40-70 \%$ of AChE activity, possibly contributing to the survival of animals after CWNA exposure.

\section{Discussion}

Taken together, the results described here demonstrate that human rePON1 produced in T. ni larvae and administered intravenously to guinea pigs protected against sarin and soman inhalation toxicities. These data support our previous observation that purified human and rabbit serum PON1 protects against CWNA toxicity (Valiyaveettil et al., 2011). The observed protective efficacy of rePON1 was reflected by the increase in survival rate, lack of behavioral symptoms, restoration of pulse rate and blood $\mathrm{O}_{2}$ saturation, significantly higher levels of blood bioscavenger enzymes and blood and brain AChE levels in pretreated animals compared to the respective nerve agent exposed controls, indicating that PON1 pretreatment decreases the overall toxicity of sarin and soman in guinea pigs. Significant protection was observed with 5 units of rePON1, which is approximately $600 \mu \mathrm{g}$ of protein per animal $(\sim 2.5 \mathrm{mg} / \mathrm{kg})$. Higher doses of rePON1, in the range of 10-20 units $(\sim 5-10 \mathrm{mg} / \mathrm{kg})$, may be adequate to efficiently protect against $2-5$ $\mathrm{X} \mathrm{LCt}_{50}$ of nerve agent exposure, which has to be confirmed by performing more detailed experiments.

As we reported earlier with human and rabbit serum PON1, the decrease in pulse rate and blood $\mathrm{O}_{2}$ saturation curves due to CWNA exposure was returned to the baseline values in rePON1 pretreated animals exposed to nerve agents, indicating that PON1 pretreatment leads to immediate restoration of normal respiration in the surviving animals (Valiyaveettil et al., 2011). Animals pretreated with rePON1 and then exposed to sarin showed a lower blood $\mathrm{O}_{2}$ saturation at 5-8 min compared to untreated animals exposed to sarin. Although this drop in blood $\mathrm{O}_{2}$ saturation was not significant, such a drop was also observed in animals pretreated with human serum purified PON1 previously (Valiyaveettil et al., 2011). In contrast, such a drop in blood $\mathrm{O}_{2}$ saturation was not observed with rabbit serum purified PON1 (Valiyaveettil et al., 2011). This might be due to the higher catalytic efficiency of rabbit serum PON1 

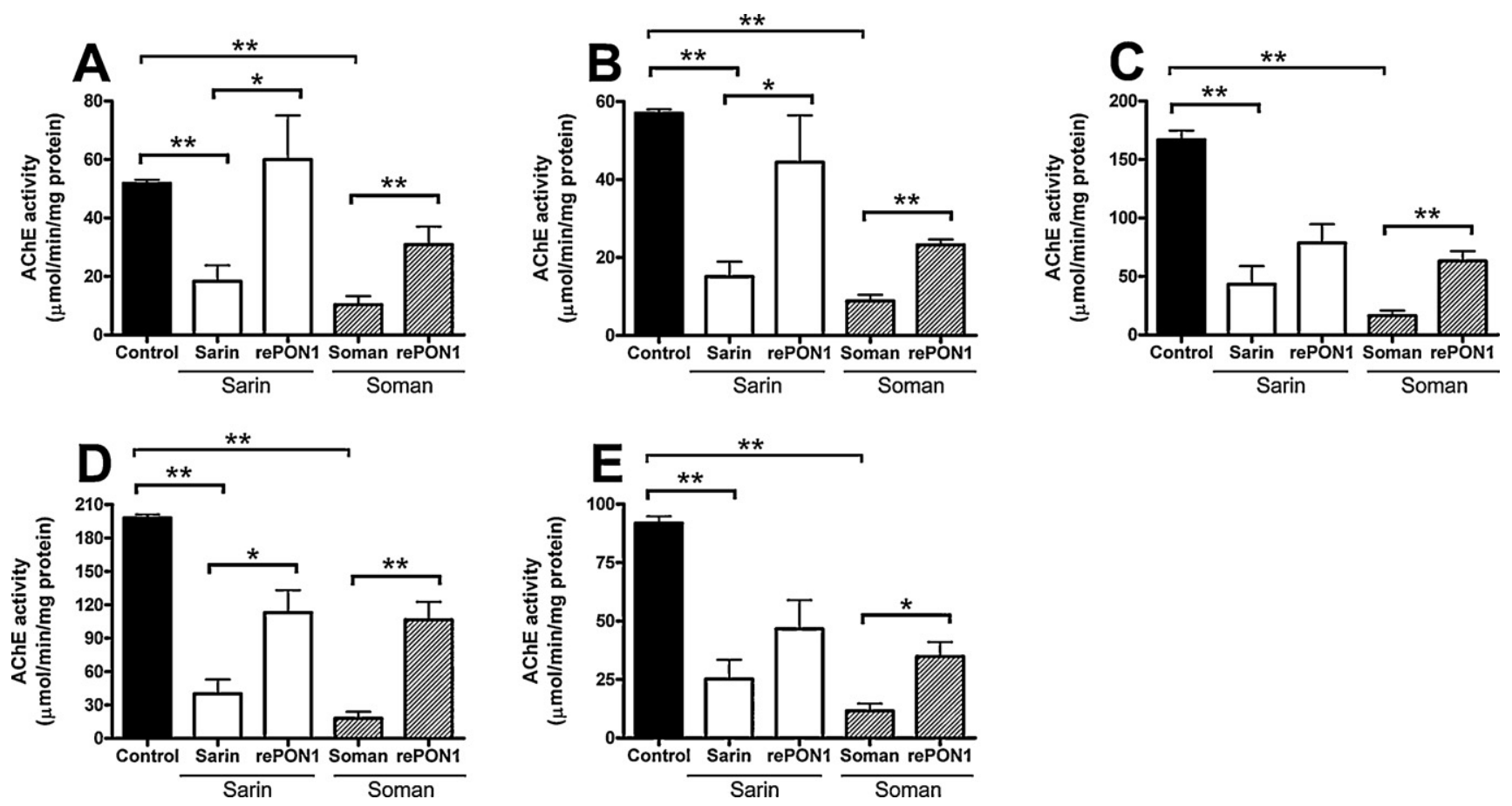

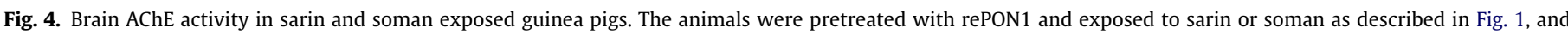

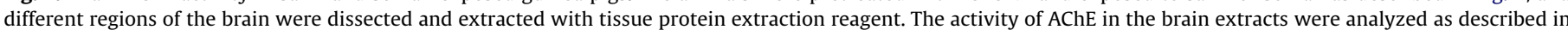

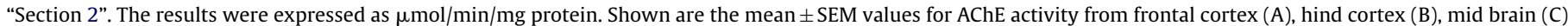
cerebellum (D), and hippocampus (E) (control unexposed, $n=6$; sarin or soman exposed, $n=6$; and rePON1, $n=4-5 ;\left({ }^{*}\right) 0.05<p<0.01 ;\left({ }^{* *}\right) 0.01<p<0.001$ ).

compared to recombinant or human serum PON1 against sarin and soman as observed earlier (Valiyaveettil et al., 2010).

Administration of rePON1 showed mild increase in the activity of PON1 in the blood of guinea pigs after $30 \mathrm{~min}$. Upon nerve agent exposure, the activities of PON1, BChE and AChE were significantly decreased in controls and rePON1 pretreated animals. However, the rePON1 pretreated animals exposed to CWNA showed significantly higher activity of blood enzymes compared to the respective agent exposed controls, indicating the in vivo hydrolysis of CWNAs by rePON1. The increased enzyme activity in the blood of rePON1 pretreated animals exposed to CWNAs can further protect the guinea pigs against repeated exposure of CWNAs. Similarly, AChE activity from different parts of the brain of rePON1 pretreated animals exposed to nerve agents was higher compared to the respective controls indicating that rePON1 pretreatment protects the central nervous system. The preservation of the activity of AChE and bioscavenger enzymes in the brain and blood of PON1 pretreated animals may be a key reason for the increased survival rate of animals.

As observed earlier with administration of purified serum PON1, intravenous injection of rePON1 showed only a minimum increase in the blood activity of the enzyme in guinea pigs after $30 \mathrm{~min}$ (Valiyaveettil et al., 2011). This might be possibly due to the rapid degradation/clearance of the exogenous PON1 in guinea pigs (Boado et al., 2011). The rapid clearance of exogenous PON1 raises the need for pharmacokinetic analysis of the rePON1 and the development of PON1 mutants with better pharmacokinetics (Boado et al., 2011). Reduced half-life of PON1 in circulation can possibly be attributed to poor association of exogenously administered PON1 with HDL, which is the natural in vivo carrier of the enzyme (Gaidukov et al., 2009; Harel et al., 2004; Sorenson et al., 1999). Modulators of PON1 which can increase the endogenous expression of the enzyme may overcome the drawback of reduced half-life associated with exogenous PON1 (Costa et al., 2011; Costa et al., 2005c). Natural association of endogenously induced PON1 with
HDL may increase the circulatory half-life of PON1. The marginal increase in the activity of PON1 with exogenous administration of recombinant or human and rabbit serum purified PON1 was sufficient to protect against $1.2 \mathrm{X} \mathrm{LCt}_{50}$ of nerve agents (Valiyaveettil et al., 2011). Dietary polyphenolic compounds such as quercetin and resveratrol are reported to increase the endogenous expression of PON1 by $2-3$ fold which possibly could be adequate to protect against lethal doses of CWNA exposure (Boesch-Saadatmandi et al., 2010; Gouedard et al., 2004).

\section{Conclusion}

In conclusion, PON1 from multiple sources (recombinant and human and rabbit serum purified) protected against $1.2 \mathrm{X} \mathrm{LCt}_{50}$ sarin and soman in guinea pigs using microinstillation inhalation exposure (Valiyaveettil et al., 2011). The protective efficacy was observed in conjunction with mild increase in the blood levels of the enzyme, possibly owing to rapid clearance of exogenous PON1. Recombinant PON1 pretreated animals retain higher levels of cholinesterase and PON1activities that might be responsible for the increased protection and survival. Research efforts to generate rePON1 with higher catalytic efficiency and enhanced pharmacokinetics can drive the future development of PON1 as catalytic bioscavenger suitable to combat against CWNA exposure.

\section{Conflict of interest statement}

The authors declare that there are no financial or personal conflicts of interest.

\section{Acknowledgements}

This work was supported by funding from Defense Threat Reduction Agency (DTRA) Grant \#1.D0017_08_WR_C. We are really 
grateful to Robert Balcerzak, Chesapeake PERL(Savage, MD) and Dr. Douglas M. Cerasoli, USAMRICD for kindly providing recombinant PON1.

\section{References}

Aldridge, W.N., Davison, A.N., 1953. The mechanism of inhibition of cholinesterases by organophosphorus compounds. Biochem. J. 55, 763-766.

Bajgar, J., 2004. Organophosphates/nerve agent poisoning: mechanism of action, diagnosis, prophylaxis, and treatment. Adv. Clin. Chem. 38, 151-216.

Boado, R.J., Hui, E.K., Lu, J.Z., Pardridge, W.M., 2011. CHO cell expression, long-term stability, and primate pharmacokinetics and brain uptake of an IgG-paroxonase1 fusion protein. Biotechnol. Bioeng. 108, 186-196.

Boesch-Saadatmandi, C., Egert, S., Schrader, C., Coumol, X., Barouki, R., Muller, M.J., Wolffram, S., Rimbach, G., 2010. Effect of quercetin on paraoxonase 1 activity studies in cultured cells, mice and humans. J. Physiol. Pharmacol. 61, 99-105.

Che, M.M., Conti, M., Boylan, M., Sciuto, A.M., Gordon, R.K., Nambiar, M.P., 2008. Blood and bronchoalveolar lavage fluid acetylcholinesterase levels following microinstillation inhalation exposure to sarin in Guinea pigs. Inhal. Toxicol. 20, 821-828.

Costa, L.G., Cole, T.B., Furlong, C.E., 2003. Polymorphisms of paraoxonase (PON1) and their significance in clinical toxicology of organophosphates. J. Toxicol. Clin. Toxicol. 41, 37-45.

Costa, L.G., Cole, T.B., Furlong, C.E., 2005a. Paraoxonase (PON1): from toxicology to cardiovascular medicine. Acta Biomed. 76 (2 Suppl.), 50-57.

Costa, L.G., Cole, T.B., Vitalone, A., Furlong, C.E., 2005b. Measurement of paraoxonase (PON1) status as a potential biomarker of susceptibility to organophosphate toxicity. Clin. Chim. Acta 352, 37-47.

Costa, L.G., Giordano, G., Furlong, C.E., 2011. Pharmacological and dietary modulators of paraoxonase 1 (PON1) activity and expression: the hunt goes on. Biochem. Pharmacol. 81, 337-344.

Costa, L.G., Vitalone, A., Cole, T.B., Furlong, C.E., 2005c. Modulation of paraoxonase (PON1) activity. Biochem. Pharmacol. 69, 541-550.

Doctor, B.P., Raveh, L., Wolfe, A.D., Maxwell, D.M., Ashani, Y., 1991. Enzymes as pretreatment drugs for organophosphate toxicity. Neurosci. Biobehav. Rev. 15, 123-128.

Doctor, B.P., Saxena, A., 2005. Bioscavengers for the protection of humans against organophosphate toxicity. Chem. Biol. Interact. 157-158, 167-171.

Duysen, E.G., Parikh, K., Aleti, V., Manne, V., Lockridge, O., Chilukuri, N., 2010. Adenovirus-mediated human paraoxonase 1 gene transfer to provide protection against the toxicity of the organophosphorus pesticide toxicant diazoxon. Gene Ther., 136, doi:10.1038/gt.2010.136.

Ellman, G.L., Courtney, K.D., Andres Jr., V., Feather-Stone, R.M., 1961. A new and rapid colorimetric determination of acetylcholinesterase activity. Biochem. Pharmacol. 7, 88-95.

Flynn, C.J., Wecker, L., 1986. Elevated choline levels in brain. A non-cholinergic component of organophosphate toxicity. Biochem. Pharmacol. 35, 3115-3121.

Fu, A.L., Wang, Y.X., Sun, M.J., 2005. Naked DNA prevents soman intoxication. Biochem. Biophys. Res. Commun. 328, 901-905.

Furlong, C.E., Cole, T.B., Walter, B.J., Shih, D.M., Tward, A., Lusis, A.J., Timchalk, C., Richter, R.J., Costa, L.G., 2005. Paraoxonase 1 (PON1) status and risk of insecticide exposure. J. Biochem. Mol. Toxicol. 19, 182-183.

Gaidukov, L., Bar, D., Yacobson, S., Naftali, E., Kaufman, O., Tabakman, R., Tawfik, D.S., Levy-Nissenbaum, E., 2009. In vivo administration of BL-3050: highly stable engineered PON1-HDL complexes. BMC. Clin. Pharmacol. 9, 18.

Gouedard, C., Barouki, R., Morel, Y., 2004. Induction of the paraoxonase-1 gene expression by resveratrol. Arterioscler. Thromb. Vasc. Biol. 24, 2378-2383.

Grillberger, L., Kreil, T.R., Nasr, S., Reiter, M., 2009. Emerging trends in plasma-free manufacturing of recombinant protein therapeutics expressed in mammalian cells. Biotechnol. J. 4, 186-201.

Harel, M., Aharoni, A., Gaidukov, L., Brumshtein, B., Khersonsky, O., Meged, R., Dvir, H., Ravelli, R.B., McCarthy, A., Toker, L., Silman, I., Sussman, J.L., Tawfik, D.S.,
2004. Structure and evolution of the serum paraoxonase family of detoxifying and anti-atherosclerotic enzymes. Nat. Struct. Mol. Biol. 11, 412-419.

Humbert, R., Adler, D.A., Disteche, C.M., Hassett, C., Omiecinski, C.J., Furlong, C.E., 1993. The molecular basis of the human serum paraoxonase activity polymorphism. Nat. Genet. 3, 73-76.

Josse, D., Masson, P., 2001. Human plasma paraoxonase (HuPON1): an antiatherogenic enzyme with organophosphate hydrolase activity. Ann. Pharm. Fr. $59,108-118$

Lenz, D.E., Maxwell, D.M., Koplovitz, I., Clark, C.R., Capacio, B.R., Cerasoli, D.M., Federko, J.M., Luo, C., Saxena, A., Doctor, B.P., Olson, C., 2005. Protection against soman or VX poisoning by human butyrylcholinesterase in guinea pigs and cynomolgus monkeys. Chem. Biol. Interact. 157-158, 205-210.

Lenz, D.E., Yeung, D., Smith, J.R., Sweeney, R.E., Lumley, L.A., Cerasoli, D.M., 2007. Stoichiometric and catalytic scavengers as protection against nerve agent toxicity: a mini review. Toxicology 233, 31-39.

Li, W.F., Furlong, C.E., Costa, L.G., 1995. Paraoxonase protects against chlorpyrifos toxicity in mice. Toxicol. Lett. 76, 219-226.

Mackness, B., Durrington, P.N., Mackness, M.I., 2002. The paraoxonase gene family and coronary heart disease. Curr. Opin. Lipidol. 13, 357-362.

Nambiar, M.P., Gordon, R.K., Moran, T.S., Richards, S.M., Sciuto, A.M., 2007. A simple method for accurate endotracheal placement of an intubation tube in Guinea pigs to assess lung injury following chemical exposure. Toxicol. Mech. Methods $17,385-392$.

Nambiar, M.P., Wright, B.S., Rezk, P.E., Smith, K.B., Gordon, R.K., Moran, T.S., Richards, S.M., Sciuto, A.M., 2006. Development of a microinstillation model of inhalation exposure to assess lung injury following exposure to toxic chemicals and nerve agents in Guinea pigs. Toxicol. Mech. Methods 16, 295-306.

Otto, T.C., Harsch, C.K., Yeung, D.T., Magliery, T.J., Cerasoli, D.M., Lenz, D.E., 2009 Dramatic differences in organophosphorus hydrolase activity between human and chimeric recombinant mammalian paraoxonase- 1 enzymes. Biochemistry 48, 10416-10422.

Otto, T.C., Kasten, S.A., Kovaleva, E., Liu, Z., Buchman, G., Tolosa, M., Davis, D., Smith J.R., Balcerzak, R., Lenz, D.E., Cerasoli, D.M., 2010. Purification and characterization of functional human paraoxonase-1 expressed in Trichoplusia ni larvae. Chem. Biol. Interact. 187, 388-392.

Perkins, M.W., Pierre, Z., Rezk, P., Sabnekar, P., Kabra, K., Chanda, S., Oguntayo, S. Sciuto, A.M., Doctor, B.P., Nambiar, M.P., 2010. Acute respiratory toxicity following inhalation exposure to soman in guinea pigs. Toxicol. Appl. Pharmacol. 245, $171-178$.

Primo-Parmo, S.L., Sorenson, R.C., Teiber, J., La Du, B.N., 1996. The human serum paraoxonase/arylesterase gene (PON1) is one member of a multigene family. Genomics 33, 498-507.

Rochu, D., Chabriere, E., Masson, P., 2007. Human paraoxonase: a promising approach for pre-treatment and therapy of organophosphorus poisoning. Toxicology 233, 47-59.

Sorenson, R.C., Bisgaier, C.L., Aviram, M., Hsu, C., Billecke, S., La Du, B.N., 1999 Human serum Paraoxonase/Arylesterase's retained hydrophobic N-terminal leader sequence associates with HDLs by binding phospholipids: apolipoprotein A-I stabilizes activity. Arterioscler. Thromb. Vasc. Biol. 19, 2214-2225.

Stevens, R.C., Suzuki, S.M., Cole, T.B., Park, S.S., Richter, R.J., Furlong, C.E., 2008. Engineered recombinant human paraoxonase 1 (rHuPON1) purified from Escherichia coli protects against organophosphate poisoning. Proc. Natl. Acad. Sci. U.S.A. 105 $12780-12784$.

Valiyaveettil, M., Alamneh, Y., Biggemann, L., Soojhawon, I., Doctor, B.P., Nambiar, M.P., 2010. Efficient hydrolysis of the chemical warfare nerve agent tabun by recombinant and purified human and rabbit serum paraoxonase 1 . Biochem. Biophys. Res. Commun. 403, 97-102.

Valiyaveettil, M., Alamneh, Y., Rezk, P., Biggemann, L., Perkins, M., Sciuto, A.M., Doctor, B.P., Nambiar, M.P., 2011. Protective efficacy of catalytic bioscavenger paraoxonase 1 against sarin and soman exposure in guinea pigs. Biochem. Pharmacol. 81, 800-809.

Wang, N.N., Dai, H., Yuan, L., Han, Z.K., Sun, J., Zhang, Z., Zhao, M., 2010. Study of paraoxonase-1 function on tissue damage of dichlorvos. Toxicol. Lett. 196, $125-132$. 